\title{
Optimization of facility location-allocation problem in customer-driven supply chain
}

\begin{abstract}
This paper develops and applies an integrated multiple criteria decision making (MCDM) approach to optimize the facility location-allocation problem in the contemporary customer-driven supply chain. Unlike the traditional optimization techniques, the proposed approach, combining the analytic hierarchy process (AHP) and the goal programming (GP) model, considers both quantitative and qualitative factors, and also aims at maximizing the benefits of deliverer and customers. In the integrated approach, the AHP is used first to determine the relative importance weightings or priorities of alternative locations with respect to both deliverer oriented and customer oriented criteria. Then, the GP model, incorporating the constraints of system, resource, and AHP priority is formulated to select the best locations for setting up the warehouses without exceeding the limited available resources. In this paper, a real case study is used to demonstrate how the integrated approach can be applied to deal with the facility location-allocation problem, and it is proved that the integrated approach outperforms the traditional cost-based approach.
\end{abstract}

Keywords: Logistics; Location-allocation; Analytic hierarchy process; Goal programming; Multiple criteria decision making 


\section{Introduction}

Facility location-allocation problem is a strategic decision problem arising in contemporary supply chain management. It is used to determine an optimal number of facilities to be established, to evaluate and select the optimal locations for setting up facilities, and also to design an optimal distribution network. Because the contemporary supply chain is customer-driven, the decision makers must consider the viewpoints of both deliverer and customer, and also consider a number of quantitative and qualitative factors. In most of the traditional optimization techniques, however, only quantifiable data were considered. Previous researchers tended to formulate the problem as mathematical models, and then apply exact algorithms or heuristic methods to solve the models. The objective function was either to minimize the total logistics cost (Louwers et al. 1999, Melkote and Daskin 2001, Nozick and Turnquist 2001, Hsieh and Tien 2004, Klimberg and Ratick 2008), total delivery distance (Gong et al. 1997) or both (Wu et al. 2002, Doong et al. 2007). Some qualitative factors, which are mainly customer oriented, were not considered.

To overcome the drawbacks, this paper develops an integrated MCDM approach, combining the AHP and GP model, to tackle the three sub-problems of the facility location-allocation decision. The integrated AHP-GP approach considers both quantitative and qualitative factors and also aims at maximizing the benefits of deliverer and customers.

A number of research projects on the integrated AHP-GP approach were found. According to the literature, it is found that the applicability of the integrated AHP-GP approach is wide. It can be applied to agriculture (Guo and He 1999), business (Schniederjans and Garvin 1997), health-care (Lee and Kwak 1999, Kwak and Lee 2002), higher education (Kwak and Lee 1998), industry (Radcliffe and Schniederjans 2003), logistics (Badri 1999, Wang et al. 2004, Wang et al. 2005, Zhou et al. 2000), manufacturing (Yurdakul 2004, Bertolini and Bevilacqua 2006), marketing (Radasch and Kwak 1998, Kwak et al. 2005), military (Kim et al. 1999), and service (Badri 2001). However, it has not been used to determine an optimal number of facilities to be established, to evaluate and select the optimal locations for setting up facilities, or to aid the design of logistics distribution network simultaneously. This is our primary motivation for writing this paper.

This paper is organized as follows. Section 2 describes the procedure of an integrated AHP-GP approach. Section 3 determines the priority rankings of alternative locations first, and then constructs a GP model for a real-world case study. Section 4 solves the model to optimality, and compares the result with that of the traditional cost-based approach. Finally, Section 5 provides concluding comments. 


\section{Integrated AHP-GP approach}

Good decisions are most often based on consistent judgments. To prevent inconsistency, the consistency verification operation of the AHP, developed by Saaty (1980), contributes greatly as it acts as a feedback mechanism for the decision makers to review and revise their judgments. Consequently, the judgments made are guaranteed to be consistent, which is a basic ingredient for making good decisions. Nevertheless, the AHP does not consider the limitations of resources in the real-world situations. For this reason, the GP, invented by Charnes and Cooper (1961), can compensate for the AHP because it makes the optimal decision based on the limited available amount of resources. To provide more and useful information for the decision makers, it is believed that the AHP and GP should be integrated together, and this is the purpose of this paper.

The integrated AHP-GP approach for the facility location-allocation problem is described as follows. The AHP is used to determine the relative importance weightings of alternative locations with respect to various evaluating criteria. After that, a GP model is formulated to select an optimal distribution network while considering the AHP priorities of locations and the quantitative-based limitations of resources. Expert Choice and LINDO are used to solve the AHP and GP, respectively. The overall procedure of the integrated approach is shown in figure 1.

In the phase of AHP, the first step is to develop the hierarchy of the location selection problem in a graphical representation, which helps to illustrate every factor that affects the performance of locations. The hierarchy lists the criteria and their alternatives level by level. Constructing a pairwise comparison matrix is intended to derive the appropriate ratio scale priorities. The relative importance of two criteria is examined one at a time. A judgment is made about which is more important and by how much. Besides criteria, every two alternatives of each criterion are compared at a time. Synthesization is carried out after all the judgments have been determined together with all the comparisons have been made. Consistency tests will be conducted to ensure that the result is accurate and reliable, and all judgments are tested and evaluated so as to have a satisfactory result. After all criteria and their corresponding attributes are compared together with all judgments are proved to be consistent, the overall priority ranking can be computed. Based on each alternative's priority and its corresponding criterion priority, the individual priority is summed to calculate the overall priority ranking. This is an input for formulating the AHP priority constraints in a GP model.

Before formulating a GP model, some real-world data on coefficients (e.g., how much 
resource an alternative consumes) and right-hand side value (e.g., how much resource is available) need to be collected. Then, the priority level of each goal is determined. After that, constraints including system, resource, and AHP priority are formulated. System constraints are ordinary linear programming constraints, in which there are no deviation variables. This type of constraints cannot be violated, and thus they are called hard constraints. Resource constraints are goal constraints or soft constraints, in which there are deviation variables. AHP priority constraints are akin to resource constraints. With this type of constraints, there are deviation variables of which the priority levels are dependent on the overall AHP priority ranking. Finally, the objective function in terms of minimizing a prioritized function of the deviation variables is developed. The GP model incorporating AHP priority constraints can be constructed as follows:

\section{Integrated AHP-GP model}

$$
\text { Minimize } z=\sum_{i} P_{i}\left(d_{i}^{+}+d_{i}^{-}\right)+\sum_{k} P_{k}\left(d_{k}^{+}+d_{k}^{-}\right)
$$

subject to

$$
\begin{array}{ll}
\sum_{j} a_{i j} x_{j} \leq b_{i} & \text { for all } i \\
\sum_{j} a_{i j} x_{j}-d_{i}^{+}+d_{i}^{-}=b_{i} & \text { for all } i \\
x_{j}-d_{k}^{+}+d_{k}^{-}=1 & \text { for all } j \\
\text { All } x_{j}=0 \text { or } 1 ; d_{i}^{+}, d_{i}^{-}, d_{k}^{+}, & \text {and } d_{k}^{-} \geq 0 .
\end{array}
$$

In the above model, $a_{i j}$ is coefficient, whereas $b_{i}$ is right-hand-side value. $d_{i}^{+}$and $d_{i}^{-}$ are over-achievement and under-achievement of goal $i$, respectively. The decision variable of the GP model is denoted as $x_{j}$. The objective function (2.1) is to minimize the total deviations from the goals, while subjecting to system constraint set (2.2) and resource constraint set (2.3). Constraint set (2.4) refers to the AHP priority constraint. The priority level $\left(P_{k}\right)$ of deviation variables $d_{k}{ }^{+}$and $d_{k}{ }^{-}$is dependent on the priority ranking of decision variable $j$, which is obtained in the AHP phase. The integrated AHP-GP model is better than the individual GP model because it also considers the relative importance of the alternatives rather than just focusing on the limitations of real-world resources. In addition, the integrated model considers both quantitative and qualitative factors. This is the major reason why this paper adopts the integrated approach. 


\section{Case study}

\subsection{AHP for location selection}

The management of a personal computer manufacturing company has forecasted that the demand of both laptop and desktop computers will increase dramatically in the next decade in China. Because the forecasted demand exceeds the capacity of the existing warehouses, setting up additional warehouses is essential. The company is evaluating five alternative regions in China, including Dongguan, Fujian, Nanjing, Shanghai, and Zhuhai, for locating additional warehouses. The criteria used to evaluate the suitability of alternative locations for setting up warehouses include proximity to stakeholders, human resources, risks, flexibility of capacity, and quality of life. These five criteria have a great impact on the profitability, productivity, and stability of the company.

\section{$\underline{\text { Proximity to stakeholders }}$}

Suppliers and customers/markets are two major logistics stakeholders with the warehouses. First, selecting a location adjacent to suppliers is beneficial to the company, especially when there is uncertainty in order cycle and demand. This helps to minimize the total lead time, and thus the accuracy of due date fulfillment can be increased. Second, the reliability of delivery time is a critical success factor in the contemporary customer-driven supply chain. Higher reliability of delivery time can enhance the satisfaction level of customers. To achieve this goal, warehouses should be located near demand markets.

\section{$\underline{\text { Human resources }}$}

Human resources consist of two sub-factors: labor availability and labor productivity. First, manpower is a crucial input of computer manufacturing, assembly, and delivery processes. The need for a pool of skilled labor is extremely important, particularly when demand rises significantly during the planning period. Second, decision makers may be tempted by a region's low labor costs when evaluating and selecting a facility location. But, employees with poor education or poor working attitudes may not be a good deal even at low costs. For example, employees in some Chinese regions are unwilling to work overtime. This may adversely affect the productivity of the company.

\section{$\underline{\text { Risks }}$}

Some risk factors should be considered when deciding on a location. They comprise the future trend of land prices (e.g., Will the prices drop dramatically in the immediate future?), 
the planning of transportation infrastructure (e.g., How often the location is congested?), the availability of utilities (e.g., Is the location always suffer from shortage of natural resources?), the probability of occurrence of strike, theft, or other devastating events in the regions, and so on. These factors, neglected in the traditional optimization techniques, are critical because they affect the competitiveness of the company directly.

\section{Flexibility of capacity}

Because location selection is a long-term decision and is made relatively infrequently, the decision makers must select a location that is capable of achieving the current and also the future production requirements. Flexibility of capacity refers to the potential of a location for expansion to respond to fluctuation in volume of customer orders.

\section{Quality of life}

A location with plenty of cultural attractions, including a world-class airport, a number of excellent hotels, shopping malls, outstanding schools, and leisure activities, is perceived to have a high quality of life. This evaluating factor is becoming increasingly important because it can attract skilled employees.

The first step of AHP for evaluating the suitability of locations is to develop a hierarchy of the decision problem, illustrated in figure 2. After constructing the hierarchy, two criteria are compared at a time with respect to the goal (from Appendix A). Once the pairwise comparisons have been made for the five criteria, each alternative location is compared against each other alternative with respect to the corresponding criterion at a time (from Appendices B to F). After completion of all pairwise comparisons, Expert Choice is used to synthesize the relative priority of each criterion and each alternative, summarized in Appendix G. The judgments are acceptable because the consistency ratios are all below the maximum 0.10 level. According to Appendix G, Shanghai or location 4 has the best overall performance because it scores the highest weighting $\left(w p_{4}=0.263\right)$, followed by Dongguan or location $1\left(w p_{1}=0.239\right)$, Zhuhai or location $5\left(w p_{5}=0.216\right)$, Fujian or location 2 $\left(w p_{2}=0.171\right)$, and Nanjing or location $3\left(w p_{3}=0.112\right)$. The AHP priorities (i.e., $\left.w p_{i}\right)$ are used to determine the priority level of the AHP priority constraints in the integrated AHP-GP model. 


\subsection{GP model for facility location-allocation problem}

Five alternative locations in China, denoted as $i=\{1,2, \ldots, m\}$, are considered to locate the additional warehouses for the growing computer manufacturing company. Each location/warehouse has a maximum throughput, $Q_{i}$, a minimum throughput, $q_{i}$, a fixed setup cost, $f c_{i}$, and a unit inventory holding cost, $h c_{i}$. Each customer, denoted as $j=\{1,2, \ldots, n\}$, has a unique order volume, $D_{j}$. When warehouse $i$ is assigned to serve customer $j$, it costs $d c_{i j}$ dollars per unit for delivery. If the total amount of products assigned to warehouse $i$ (i.e., $\left.\sum_{j=1}^{n} x_{i j}, \forall i\right)$ is less than $q_{i}$, this is an impractical allocation because it is not cost-effective to set up a warehouse for processing only a few orders. To avoid low effectiveness of warehouse utilization, penalty cost, $p c_{i}$, is considered in the model, which is incurred if $0<\sum_{j=1}^{n} x_{i j}<q_{i}$. The problem here is to determine an optimal number of warehouses to be set up, to select the optimal locations for setting up the warehouses, and to yield an optimal distribution network, which refers to the allocation of orders to the best warehouses. In the model, there are four types of decision variables:

$$
\begin{aligned}
x_{i j} & =\text { amount of products delivered from warehouse } i \text { to customer } j \\
u_{i} & = \begin{cases}1 & \text { if total allocation of products to warehouse } i \text { is less than } q_{i} \\
0 & \text { otherwise }\end{cases} \\
v_{i} & = \begin{cases}1 & \text { if location } i \text { is selected to set up a warehouse } \\
0 & \text { otherwise }\end{cases} \\
w_{i} & = \begin{cases}1 & \text { if both } u_{i} \text { and } v_{i} \text { equal to one } \\
0 & \text { otherwise }\end{cases}
\end{aligned}
$$

Before formulating the integrated model for the facility location-allocation problem, data on coefficients and right-hand side value should be collected. The necessary resource data is presented in table 1 . The system constraints, resource constraints, AHP priority constraints, and objective function of the integrated model are shown in the following, whereas the integrated model using the data presented in table 1 is formulated in Appendix $\mathrm{H}$.

\section{System constraints}

Determine which warehouse(s) has/have allocation of products that less than minimum warehouse throughput:

$$
\sum_{j=1}^{n} x_{i j}+M u_{i} \geq q_{i}, \forall i
$$


Determine which location(s) is/are selected:

$$
\sum_{j=1}^{n} x_{i j}-M v_{i} \leq 0, \forall i
$$

Determine which warehouse(s) incur(s) penalty cost:

$$
w_{i}-u_{i}-v_{i}=-1, \forall i
$$

\section{$\underline{\text { Resource constraints }}$}

Priority level $1\left(P_{1}\right)$ : (a) Allocate products to warehouses while the amount must not exceed the maximum warehouse throughput:

$$
\sum_{j=1}^{n} x_{i j}-d_{i}^{+}+d_{i}^{-}=Q_{i}, \forall i
$$

(b) Allocate products to warehouses while the amount must be equal to that demanded by the customers:

$$
\sum_{i=1}^{m} x_{i j}-d_{j+m}^{+}+d_{j+m}^{-}=D_{j}, \forall j
$$

Priority level $2\left(P_{2}\right)$ : The total cost, including the inventory holding cost, delivery cost, and fixed setup cost associated with location selection, must not exceed the targeted amount:

$$
\sum_{i=1}^{m} \sum_{j=1}^{n}\left(h c_{i}+d c_{i j}\right) x_{i j}+\sum_{i=1}^{m} f c_{i} v_{i}-d_{m+n+1}^{+}+d_{m+n+1}^{-}=T C
$$

Priority level $3\left(P_{3}\right)$ : Allocation of products to warehouses incurring penalty cost is not allowed:

$$
\sum_{i=1}^{m} p c_{i} w_{i}-d_{m+n+2}^{+}+d_{m+n+2}^{-}=0
$$

\section{$\underline{\text { AHP priority constraints }}$}

Priority levels 4 to $m+3\left(P_{4}\right.$ to $\left.P_{m+3}\right)$ : Set up a warehouse in location $i$ (Note that locations with higher AHP priorities are at the higher priority levels)

$$
v_{i}-d_{k}^{+}+d_{k}^{-}=1, \forall i
$$

\section{Objective function}

The objective function is to minimize the total deviations from the goals.

$$
\text { Minimize } z=\sum_{i} P_{i}\left(d_{i}^{+}+d_{i}^{-}\right)+\sum_{k} P_{k}\left(d_{k}^{+}+d_{k}^{-}\right)
$$




\section{$4 \quad$ Result analysis}

Because the integrated AHP-GP model consists of integral decision variables (i.e., $x_{i j}$, $u_{i}$, $v_{i}$, and $w_{i}$ ) and fractional decision variables (i.e., $d_{i}^{+}$and $d_{i}^{-}$), it is a mixed integer linear programming model. In the integrated model, as shown in Appendix H, there are 50 integral decision variables, 38 deviation variables, 34 constraints, and eight goals. The solution, solved using LINDO, is shown in table 2. The computational time spent on a $3.4 \mathrm{GHz}$ computer is less than one second. It is a feasible solution because the allocation does not exceed the maximum throughput of warehouses, does satisfy the volume requirement of customers, does not exceed the total cost budget, and does not incur any penalty cost. When priority level 7 was found to be unachievable $\left(d_{18}^{-}=1\right)$, the optimization process was terminated. So, the solution, satisfying the first six priority levels (i.e., $P_{1}$ to $P_{6}$ ), is an optimal solution of the problem. The values of decision variables $v_{i}$ show that three locations were selected to set up additional warehouses, including location 1 (i.e., Dongguan), location 4 (i.e., Shanghai), and location 5 (i.e., Zhuhai). The total cost spent in setting up these three warehouses, holding inventory in the warehouses, and delivering products from the warehouses to their assigned customers is $\$ 458000$ with no slack. Besides, the total penalty cost incurred is zero. Priority level 7 could not be achieved because of constraint set (A.28).

The solution generated is satisfactory because the three best locations (i.e., Shanghai, Dongguan, and Zhuhai) were selected. In addition, the summation of AHP priorities of the

selected locations is high $\left(\sum w p_{i}=0.718\right.$, here $i$ represents locations 1,4 , and 5 ). This model can lead to an optimal location-allocation solution and win-win situation. Because locations with better conditions, such as located near the supply chain stakeholders, sufficient supply of skilled labor, lower risks, higher flexibility, and better quality of life, are given priority, the total lead time can be minimized and the accuracy of order fulfillment can be increased. These are the two major ingredients of enhancing the satisfaction level of customers and also the competitiveness of deliverer in the contemporary supply chain management. Besides focusing on the qualitative factors, some cost factors are considered in the model, including the fixed setup cost, delivery cost, inventory holding cost, and penalty cost. The selected locations as well as distribution network must be cost-effective.

The comparison between AHP priority ranking and the optimal solutions of the traditional cost-based and integrated AHP-GP models is summarized in table 3. Note that the optimal solution of the cost-based model can be solved using the GP model from priority levels 1 to 3 [i.e., constraint sets (A.1) to (A.29)]. Its solution is: $x_{11}=7000, x_{13}=10000, x_{16}$ 
$=4000, x_{25}=6000, x_{26}=7000, x_{27}=7000, x_{51}=5000, x_{52}=9000$, and $x_{54}=8000$. It is found that the total cost of the optimal solution of the cost-based model is exactly the same as that of the integrated model, \$458000. However, the summation of AHP priorities of the selected warehouses in the cost-based model is lower than that in the integrated model, 0.626 vs. 0.718. It is because the best location (i.e., Shanghai) was not selected. Therefore, it can be proved that the solutions generated by the traditional cost-based approach may not be cost-effective. It is because the qualitative factors affecting the company's profitability, productivity, and stability are not considered.

\section{Conclusions}

In the contemporary customer-driven supply chain, any approaches aiming at maximizing the benefits of the points of supply only, and neglecting the viewpoints of customers may not yield a realistic solution of the facility location-allocation problem. In addition, besides cost factors, various qualitative factors should be considered when deciding on a location, including proximity to stakeholders, human resources, risks, flexibility of capacity, and quality of life. To achieve this goal, this paper developed an integrated MCDM approach, combining the AHP and GP, for the problem. Besides achieving the goals of deliverer, the proposed approach aims at enhancing the satisfaction level of customers. The higher the satisfaction level is, the higher the chance for the customers to repeat orders.

In the integrated approach, the AHP was used first to determine the relative importance weightings of alternative locations with respect to the five evaluating criteria. The relative importance weightings or the AHP priorities represent the ability of the locations in maximizing the benefits of the company and its customers. After assigning priorities to the locations, the GP model incorporating the AHP priority, system, and resource constraints was formulated to select the best locations for setting up the warehouses while considering the fixed setup cost, inventory holding cost, delivery cost, and penalty cost. The major advantages of this integrated approach are that both quantitative and qualitative factors are considered simultaneously and also the viewpoints of deliverer and customers are focused. Therefore, it is believed that this approach must be more practical and applicable than the traditional optimization techniques, which focused on quantitative factors only.

\section{Acknowledgments}

The authors wish to thank the Research Grants Council of Hong Kong Special Administrative Region, China for the financial support. 


\section{References}

Badri MA (1999) Combining the analytic hierarchy process and goal programming for global facility location-allocation problem. International Journal of Production Economics 62:237-248.

Badri MA (2001) A combined AHP-GP model for quality control systems. International Journal of Production Economics 72:27-40.

Bertolini M, Bevilacqua M (2006) A combined goal programming-AHP approach to maintenance selection problem. Reliability Engineering and System Safety 91:839-848.

Charnes A, Cooper WW (1961) Management models and industrial applications of linear programming. John Wiley \& Sons, New York.

Doong SH, Lai CC, Wu CH (2007) Genetic subgradient method for solving location-allocation problems. Applied Soft Computing 7:373-386.

Gong D, Gen M, Yamazaki G, Xu W (1997) Hybrid evolutionary method for capacitated location-allocation problem. Computers \& Industrial Engineering 33:577-580.

Guo LS, He YS (1999) Integrated multi-criterial decision model: a case study for the allocation of facilities in Chinese agriculture. Journal of Agricultural Engineering Research 73:87-94.

Ho W (2008) Integrated analytic hierarchy process and its applications - a literature review. European Journal of Operational Research 186:211-228.

Hsieh KH, Tien FC (2004) Self-organizing feature maps for solving location-allocation problems with rectilinear distances. Computers \& Operations Research 31:1017-1031.

Kim PO, Lee KJ, Lee BW (1999) Selection of an optimal nuclear fuel cycle scenario by goal programming and the analytic hierarchy process. Annals of Nuclear Energy 26:449-460.

Klimberg RK, Ratick SJ (2008) Modeling data envelopment analysis (DEA) efficient location/allocation decisions. Computers \& Operations Research 35:457-474.

Kwak NK, Lee CW (1998) A multicriteria decision-making approach to university resource allocations and information infrastructure planning. European Journal of Operational Research 110:234-242.

Kwak NK, Lee CW (2002) Business process reengineering for health-care system using multicriteria mathematical programming. European Journal of Operational Research 140:447-458.

Kwak NK, Lee CW, Kim JH (2005) An MCDM model for media selection in the dual 
consumer/industrial market. European Journal of Operational Research 166:255-265.

Lee CW, Kwak NK (1999) Information resource planning for a health-care system using an AHP-based goal programming method. Journal of the Operational Research Society 50:1191-1198.

Louwers D, Kip BJ, Peters E, Souren F, Flapper SDP (1999) A facility location allocation model for reusing carpet materials. Computers \& Industrial Engineering 36:855-869.

Melkote S, Daskin MS (2001) An integrated model of facility location and transportation network design. Transportation Research Part A 35:515-538.

Nozick LK, Turnquist MA (2001) A two-echelon inventory allocation and distribution center location analysis. Transportation Research Part E 37:425-441.

Radasch DK, Kwak NK (1998) An integrated mathematical programming model for offset planning. Computers \& Operations Research 25:1069-1083.

Radcliffe LL, Schniederjans MJ (2003) Trust evaluation: an AHP and multi-objective programming approach. Management Decision 41:587-595.

Saaty TL (1980) The analytic hierarchy process. McGraw-Hill, New York.

Schniederjans MJ, Garvin T (1997) Using the analytic hierarchy process and multi-objective programming for the selection of cost drivers in activity-based costing. European Journal of Operational Research 100:72-80.

Wang G, Huang SH, Dismukes JP (2004) Product-driven supply chain selection using integrated multi-criteria decision-making methodology. International Journal of Production Economics 91:1-15.

Wang G, Huang SH, Dismukes JP (2005) Manufacturing supply chain design and evaluation. International Journal of Advanced Manufacturing Technology 25:93-100.

Wu TH, Low C, Bai JW (2002) Heuristic solutions to multi-depot location-routing problems. Computers \& Operations Research 29:1393-1415.

Yurdakul M (2004) Selection of computer-integrated manufacturing technologies using a combined analytic hierarchy process and goal programming model. Robotics and Computer-Integrated Manufacturing 20:329-340.

Zhou Z, Cheng S, Hua B (2000) Supply chain optimization of continuous process industries with sustainability considerations. Computers and Chemical Engineering 24:1151-1158. 

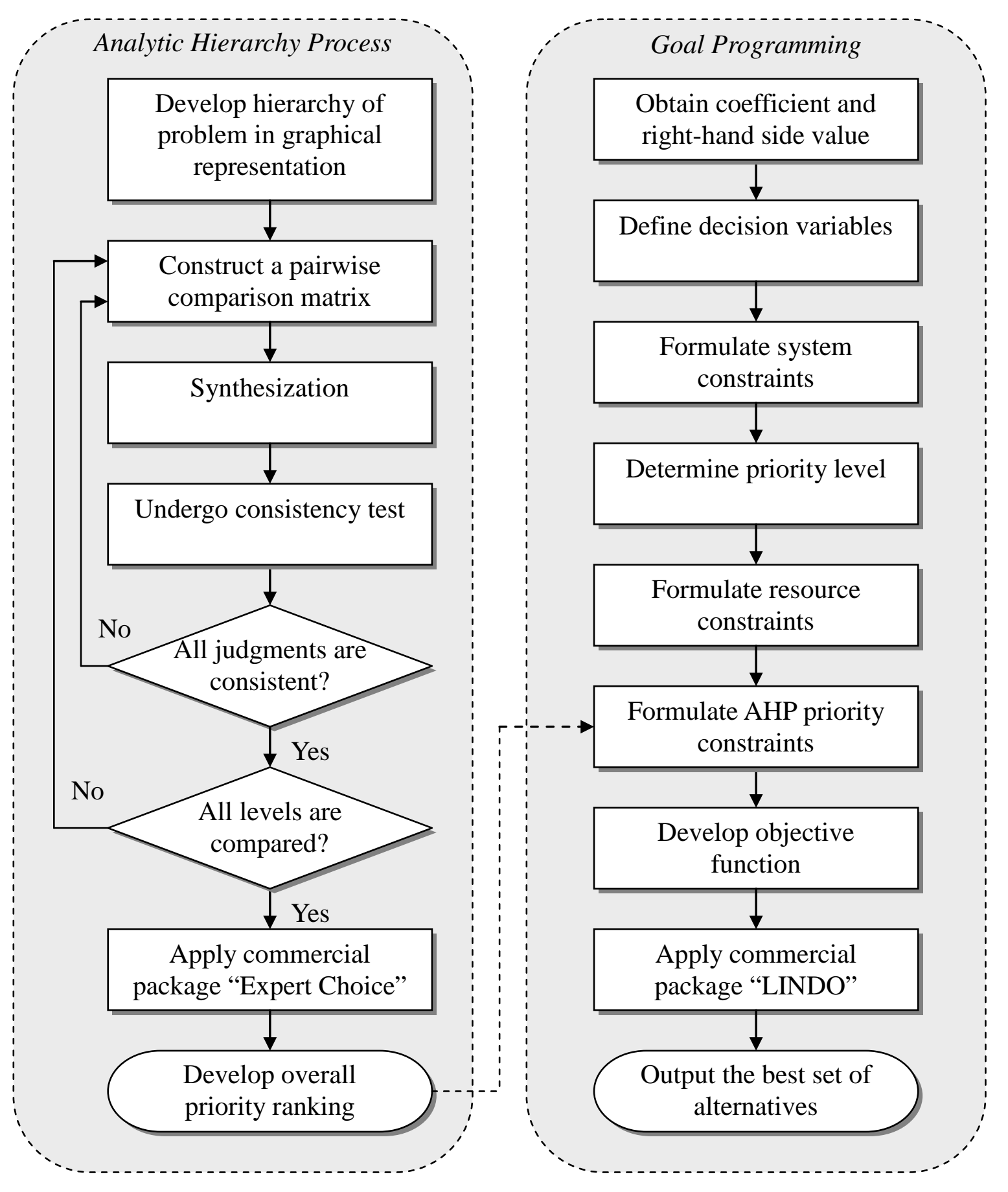

Fig 1 The flowchart of the integrated MCDM approach (Ho 2008) 
Goal:

Criteria:

Sub-factors:

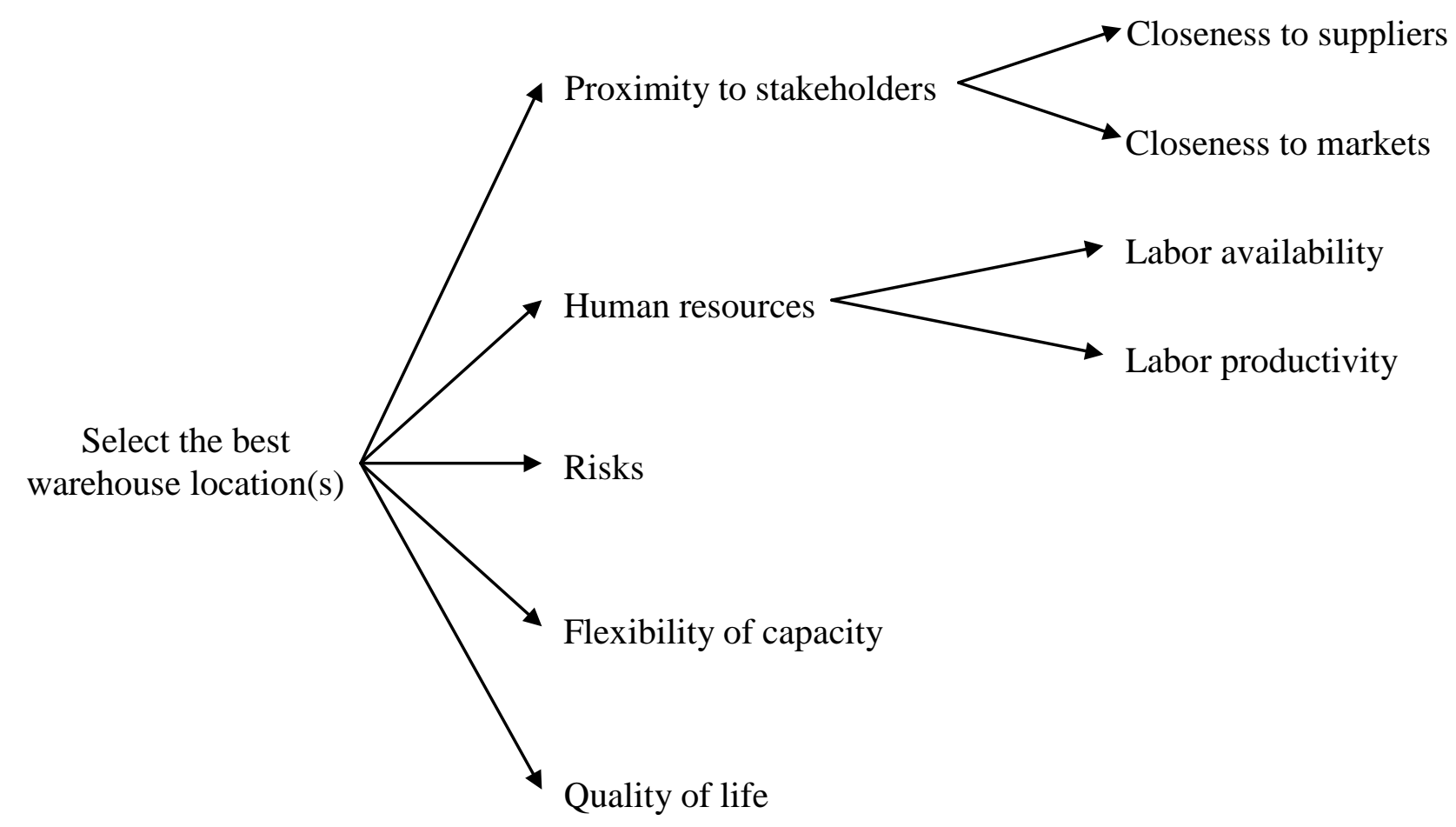

Alternatives:

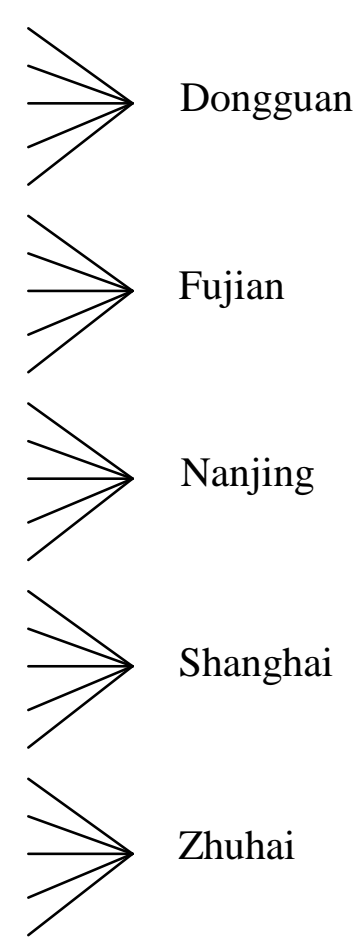

Fig 2 The hierarchy of the location selection problem 
Table 1 Resource data for the integrated model

\begin{tabular}{|c|c|c|c|c|c|c|c|c|c|c|c|c|}
\hline \multirow{2}{*}{ Location, $i$} & \multicolumn{7}{|c|}{ Unit delivery cost (\$), $d c_{i j}$} & \multirow{2}{*}{$\begin{array}{c}\text { Maximum } \\
\text { throughput of } \\
\text { warehouse } i \text {, } \\
\qquad Q_{i}\end{array}$} & \multirow{2}{*}{$\begin{array}{c}\text { Minimum } \\
\text { throughput of } \\
\text { warehouse } i \text {, } \\
q_{i}\end{array}$} & \multirow{2}{*}{$\begin{array}{c}\text { Unit } \\
\text { holding } \\
\text { cost (\$), } \\
h c_{i}\end{array}$} & \multirow{2}{*}{$\begin{array}{c}\text { Fixed } \\
\text { setup } \\
\text { cost (\$), } \\
\quad f_{i}\end{array}$} & \multirow{2}{*}{$\begin{array}{c}\text { Penalty } \\
\text { cost (\$) } \\
p c_{i}\end{array}$} \\
\hline & \multicolumn{7}{|c|}{ Customer, $j$} & & & & & \\
\hline 1 (Dongguan) & 1 & 2 & 4 & 4 & 5 & 7 & 7 & 30000 & 6000 & 2 & 15000 & 3000 \\
\hline 2 (Fujian) & 3 & 1 & 5 & 3 & 3 & 7 & 6 & 20000 & 4000 & 3 & 20000 & 5000 \\
\hline 4 (Shanghai) & 8 & 4 & 8 & 4 & 1 & 8 & 4 & 20000 & 4000 & 5 & 30000 & 7000 \\
\hline 5 (Zhuhai) & 2 & 1 & 5 & 4 & 5 & 8 & 7 & 30000 & 6000 & 3 & 20000 & 4000 \\
\hline $\begin{array}{l}\text { Amount demanded } \\
\text { by customer } j, D_{j}\end{array}$ & 12000 & 9000 & 10000 & 8000 & 6000 & 11000 & 7000 & & & & & \\
\hline
\end{tabular}

Targeted total cost, $T C=\$ 458000$; Arbitrary large number, $M=100000$. 
Table 2 Optimal solution of the integrated model

\begin{tabular}{|c|c|c|c|c|c|c|c|c|c|c|c|}
\hline \multirow[t]{2}{*}{$\begin{array}{c}\text { Goal } \\
\text { priority }\end{array}$} & \multirow[t]{2}{*}{$\begin{array}{c}\text { Goal } \\
\text { achievement }\end{array}$} & \multirow{2}{*}{$\begin{array}{c}\text { Solutions: } \\
\text { i }\end{array}$} & \multicolumn{7}{|c|}{$\begin{array}{c}\text { Allocation of products, } x_{i j} \\
j\end{array}$} & \multirow[b]{2}{*}{$v_{i}$} & \multirow{2}{*}{$\begin{array}{c}\sum \text { (fixed setup cost }_{i} \\
+ \text { inventory holding cost }_{i} \\
\left.+ \text { delivery cost }_{i}\right)\end{array}$} \\
\hline & & & 1 & 2 & 3 & 4 & 5 & 6 & 7 & & \\
\hline \multirow[t]{6}{*}{$P_{1}$ to $P_{6}$} & Achieved & 1 & 9000 & - & 10000 & - & - & 11000 & - & 1 & $\$ 201,000$ \\
\hline & & 2 & - & - & - & - & - & - & - & 0 & N/A \\
\hline & & 3 & - & - & - & - & - & - & - & 0 & N/A \\
\hline & & 4 & - & - & - & 500 & 6000 & - & 7000 & 1 & $\$ 133,500$ \\
\hline & & 5 & 3000 & 9000 & - & 7500 & - & - & - & 1 & $\$ 123,500$ \\
\hline & & & & & & & & & & Total & $\$ 458,000$ \\
\hline$P_{7}$ & Not achieved & & & & & & & & & & \\
\hline$P_{8}$ & Not achieved & & & & & & & & & & \\
\hline
\end{tabular}


Table 3 Comparison between AHP priority ranking and the optimal solutions

\begin{tabular}{ccccc}
\hline Warehouses & $w p_{i}$ & $\begin{array}{c}\text { AHP priority } \\
\text { ranking }\end{array}$ & $\begin{array}{c}\text { Cost-based } \\
\text { model }\end{array}$ & $\begin{array}{c}\text { Integrated } \\
\text { AHP-GP model }\end{array}$ \\
\hline 1 & 0.239 & 2nd & Selected & Selected \\
2 & 0.171 & 4 th & Selected & Not selected \\
3 & 0.112 & 5 th & Not selected & Not selected \\
4 & 0.263 & 1 st & Not selected & Selected \\
5 & 0.216 & 3rd & Selected & Selected \\
\hline
\end{tabular}


Appendix A: Priorities of criteria with respect to goal

\begin{tabular}{ccccccccccc}
\hline & C1 & C2 & C3 & C4 & C5 & Priorities & $\lambda_{\max }$ & $C I$ & $R I$ & $C R$ \\
\hline C1 & 1 & 2 & 2 & 4 & 3 & 0.375 & & & & \\
C2 & $1 / 2$ & 1 & 2 & 3 & 2 & 0.251 & & & & \\
C3 & $1 / 2$ & $1 / 2$ & 1 & 2 & 2 & 0.172 & & & & \\
C4 & $1 / 4$ & $1 / 3$ & $1 / 2$ & 1 & 2 & 0.108 & & & & \\
C5 & $1 / 3$ & $1 / 2$ & $1 / 2$ & $1 / 2$ & 1 & 0.094 & & & & \\
& & & & & Total & 1.000 & 5.165 & 0.041 & 1.120 & 0.037 \\
\hline
\end{tabular}

C1: Proximity to stakeholders; C2: Human resources; C3: Risks; C4: Flexibility of capacity; C5: Quality of life. 
Appendix B: Priorities of alternatives with respect to proximity to stakeholders

\begin{tabular}{|c|c|c|c|c|c|c|c|c|c|c|}
\hline & A1 & $\mathrm{A} 2$ & A3 & A4 & A5 & Priorities & $\lambda_{\max }$ & $C I$ & $R I$ & $C R$ \\
\hline \multicolumn{11}{|c|}{ Closeness to suppliers: } \\
\hline A1 & 1 & 2 & 4 & 3 & 1 & 0.326 & & & & \\
\hline $\mathrm{A} 2$ & $1 / 2$ & 1 & 3 & 2 & $1 / 2$ & 0.190 & & & & \\
\hline A3 & $1 / 4$ & $1 / 3$ & 1 & $1 / 2$ & $1 / 3$ & 0.074 & & & & \\
\hline A4 & $1 / 3$ & $1 / 2$ & 2 & 1 & $1 / 2$ & 0.122 & & & & \\
\hline \multirow[t]{2}{*}{ A5 } & 1 & 2 & 3 & 2 & 1 & 0.288 & & & & \\
\hline & & & & & Total & 1.000 & 5.072 & 0.018 & 1.120 & 0.016 \\
\hline \multicolumn{11}{|c|}{ Closeness to markets: } \\
\hline A1 & 1 & $1 / 2$ & $1 / 2$ & $1 / 3$ & 2 & 0.126 & & & & \\
\hline A2 & 2 & 1 & 2 & $1 / 2$ & 2 & 0.238 & & & & \\
\hline A3 & 2 & $1 / 2$ & 1 & $1 / 2$ & 2 & 0.179 & & & & \\
\hline A4 & 3 & 2 & 2 & 1 & 3 & 0.362 & & & & \\
\hline \multirow[t]{2}{*}{ A5 } & $1 / 2$ & $1 / 2$ & $1 / 2$ & $1 / 3$ & 1 & 0.095 & & & & \\
\hline & & & & & Total & 1.000 & 5.131 & 0.033 & 1.120 & 0.029 \\
\hline
\end{tabular}

A1: Dongguan; A2: Fujian; A3: Nanjing; A4: Shanghai; A5: Zhuhai. 
Appendix C: Priorities of alternatives with respect to human resources

\begin{tabular}{ccccccccccc}
\hline \multicolumn{2}{c}{ A1 } & A2 & A3 & A4 & A5 & Priorities & $\lambda_{\max }$ & CI & $R I$ & CR \\
\hline Labor availability: & 1 & 2 & 3 & 2 & 1 & 0.294 & & & & \\
A1 & 1 & 1 & 3 & 2 & $1 / 2$ & 0.197 & & & & \\
A2 & $1 / 2$ & $1 / 3$ & 1 & $1 / 2$ & $1 / 3$ & 0.081 & & & & \\
A3 & $1 / 3$ & $1 / 3$ & & & & & & \\
A4 & $1 / 2$ & $1 / 2$ & 2 & 1 & $1 / 2$ & 0.135 & & & & \\
A5 & 1 & 2 & 3 & 2 & 1 & 0.294 & & & & \\
& & & & & Total & 1.000 & 5.088 & 0.022 & 1.120 & 0.020 \\
Labor productivity: & & & & & & & & \\
A1 & 1 & 2 & 3 & $1 / 2$ & 2 & 0.251 & & & & \\
A2 & $1 / 2$ & 1 & 2 & $1 / 3$ & $1 / 2$ & 0.121 & & & & \\
A3 & $1 / 3$ & $1 / 2$ & 1 & $1 / 3$ & $1 / 3$ & 0.079 & & & & \\
A4 & 2 & 3 & 3 & 1 & 2 & 0.359 & & & & \\
A5 & $1 / 2$ & 2 & 3 & $1 / 2$ & 1 & 0.190 & & & & \\
& & & & & Total & 1.000 & 5.130 & 0.033 & 1.120 & 0.029 \\
\hline
\end{tabular}


Appendix D: Priorities of alternatives with respect to risks

\begin{tabular}{ccccccccccc}
\hline & A1 & A2 & A3 & A4 & A5 & Priorities & $\lambda_{\max }$ & $C I$ & $R I$ & $C R$ \\
\hline A1 & 1 & 3 & 2 & $1 / 2$ & 2 & 0.253 & & & & \\
A2 & $1 / 3$ & 1 & $1 / 2$ & $1 / 4$ & $1 / 3$ & 0.073 & & & & \\
A3 & $1 / 2$ & 2 & 1 & $1 / 2$ & $1 / 2$ & 0.132 & & & & \\
A4 & 2 & 4 & 2 & 1 & 2 & 0.351 & & & & \\
A5 & $1 / 2$ & 3 & 2 & $1 / 2$ & 1 & 0.191 & & & & \\
& & & & & Total & 1.000 & 5.118 & 0.029 & 1.120 & 0.026 \\
\hline
\end{tabular}

Appendix E: Priorities of alternatives with respect to flexibility of capacity

\begin{tabular}{ccccccccccc}
\hline & A1 & A2 & A3 & A4 & A5 & Priorities & $\lambda_{\max }$ & $C I$ & $R I$ & $C R$ \\
\hline A1 & 1 & 2 & 3 & 2 & 1 & 0.295 & & & & \\
A2 & $1 / 2$ & 1 & 2 & 2 & $1 / 2$ & 0.184 & & & & \\
A3 & $1 / 3$ & $1 / 2$ & 1 & $1 / 2$ & $1 / 3$ & 0.088 & & & & \\
A4 & $1 / 2$ & $1 / 2$ & 2 & 1 & $1 / 2$ & 0.138 & & & & \\
A5 & 1 & 2 & 3 & 2 & 1 & 0.295 & & & & \\
& & & & & Total & 1.000 & 5.072 & 0.018 & 1.120 & 0.016 \\
\hline
\end{tabular}

Appendix F: Priorities of alternatives with respect to quality of life

\begin{tabular}{ccccccccccc}
\hline & A1 & A2 & A3 & A4 & A5 & Priorities & $\lambda_{\max }$ & $C I$ & $R I$ & $C R$ \\
\hline A1 & 1 & 2 & 3 & $1 / 3$ & $1 / 2$ & 0.163 & & & & \\
A2 & $1 / 2$ & 1 & 2 & $1 / 4$ & $1 / 2$ & 0.106 & & & & \\
A3 & $1 / 3$ & $1 / 2$ & 1 & $1 / 4$ & $1 / 3$ & 0.070 & & & & \\
A4 & 3 & 4 & 4 & 1 & 3 & 0.444 & & & & \\
A5 & 2 & 2 & 3 & $1 / 3$ & 1 & 0.216 & & & & \\
& & & & & Total & 1.000 & 5.152 & 0.038 & 1.120 & 0.034 \\
\hline
\end{tabular}


Appendix G: Data analysis for the location selection problem

\begin{tabular}{|c|c|c|c|c|c|c|c|c|c|}
\hline \multirow[b]{2}{*}{ Criteria } & \multirow[b]{2}{*}{ Weights } & \multirow[b]{2}{*}{ Sub-factors } & \multirow[b]{2}{*}{ Weights } & \multirow[b]{2}{*}{$\begin{array}{l}\text { Normalized } \\
\text { weights of } \\
\text { sub-factors }\end{array}$} & \multicolumn{5}{|c|}{ Alternatives } \\
\hline & & & & & Dongguan & Fujian & Nanjing & Shanghai & Zhuhai \\
\hline $\begin{array}{l}\text { Proximity to } \\
\text { stakeholders }\end{array}$ & 0.375 & $\begin{array}{l}\text { Closeness to } \\
\text { suppliers }\end{array}$ & 0.333 & 0.125 & 0.326 & 0.190 & 0.074 & 0.122 & 0.288 \\
\hline \multirow[t]{2}{*}{$\begin{array}{l}\text { Human } \\
\text { resources }\end{array}$} & 0.251 & $\begin{array}{l}\text { Labor } \\
\text { availability }\end{array}$ & 0.667 & 0.167 & 0.294 & 0.197 & 0.081 & 0.135 & 0.294 \\
\hline & & $\begin{array}{l}\text { Labor } \\
\text { productivity }\end{array}$ & 0.333 & 0.084 & 0.251 & 0.121 & 0.079 & 0.359 & 0.190 \\
\hline \multirow[t]{3}{*}{ Quality of life } & 0.094 & & & & 0.163 & 0.106 & 0.070 & 0.444 & 0.216 \\
\hline & & & Ove & all weightings & 0.239 & 0.171 & 0.112 & 0.263 & 0.216 \\
\hline & & & & Ranking & 2nd & 4th & 5th & $1 s t$ & 3rd \\
\hline
\end{tabular}




\section{Appendix H: Integrated AHP-GP model}

The integrated AHP-GP model for the example given in Section 3.2 is as follows.

\section{Constraints}

$$
\begin{aligned}
& x_{11}+x_{12}+x_{13}+x_{14}+x_{15}+x_{16}+x_{17}+100000 u_{1} \geq 6000 \\
& x_{21}+x_{22}+x_{23}+x_{24}+x_{25}+x_{26}+x_{27}+100000 u_{2} \geq 4000 \\
& x_{31}+x_{32}+x_{33}+x_{34}+x_{35}+x_{36}+x_{37}+100000 u_{3} \geq 4000 \\
& x_{41}+x_{42}+x_{43}+x_{44}+x_{45}+x_{46}+x_{47}+100000 u_{4} \geq 4000 \\
& x_{51}+x_{52}+x_{53}+x_{54}+x_{55}+x_{56}+x_{57}+100000 u_{5} \geq 6000 \\
& x_{11}+x_{12}+x_{13}+x_{14}+x_{15}+x_{16}+x_{17}-100000 v_{1} \leq 0 \\
& x_{21}+x_{22}+x_{23}+x_{24}+x_{25}+x_{26}+x_{27}-100000 v_{2} \leq 0 \\
& x_{31}+x_{32}+x_{33}+x_{34}+x_{35}+x_{36}+x_{37}-100000 v_{3} \leq 0 \\
& x_{41}+x_{42}+x_{43}+x_{44}+x_{45}+x_{46}+x_{47}-100000 v_{4} \leq 0 \\
& x_{51}+x_{52}+x_{53}+x_{54}+x_{55}+x_{56}+x_{57}-100000 v_{5} \leq 0 \\
& w_{1}-u_{1}-v_{1}=-1 \\
& w_{2}-u_{2}-v_{2}=-1 \\
& w_{3}-u_{3}-v_{3}=-1 \\
& w_{4}-u_{4}-v_{4}=-1 \\
& w_{5}-u_{5}-v_{5}=-1 \\
& x_{11}+x_{12}+x_{13}+x_{14}+x_{15}+x_{16}+x_{17}-d_{1}^{+}+d_{1}^{-}=30000 \\
& x_{21}+x_{22}+x_{23}+x_{24}+x_{25}+x_{26}+x_{27}-d_{2}^{+}+d_{2}^{-}=20000 \\
& x_{31}+x_{32}+x_{33}+x_{34}+x_{35}+x_{36}+x_{37}-d_{3}^{+}+d_{3}^{-}=20000 \\
& x_{41}+x_{42}+x_{43}+x_{44}+x_{45}+x_{46}+x_{47}-d_{4}^{+}+d_{4}^{-}=20000 \\
& x_{51}+x_{52}+x_{53}+x_{54}+x_{55}+x_{56}+x_{57}-d_{5}^{+}+d_{5}^{-}=30000 \\
& x_{11}+x_{21}+x_{31}+x_{41}+x_{51}-d_{6}^{+}+d_{6}^{-}=12000 \\
& x_{12}+x_{22}+x_{32}+x_{42}+x_{52}-d_{7}^{+}+d_{7}^{-}=9000 \\
& x_{13}+x_{23}+x_{33}+x_{43}+x_{53}-d_{8}^{+}+d_{8}^{-}=10000 \\
& x_{14}+x_{24}+x_{34}+x_{44}+x_{54}-d_{9}^{+}+d_{9}^{-}=8000 \\
& x_{15}+x_{25}+x_{35}+x_{45}+x_{55}-d_{10}^{+}+d_{10}^{-}=6000
\end{aligned}
$$




$$
\begin{aligned}
& x_{16}+x_{26}+x_{36}+x_{46}+x_{56}-d_{11}^{+}+d_{11}^{-}=11000 \\
& x_{17}+x_{27}+x_{37}+x_{47}+x_{57}-d_{12}^{+}+d_{12}^{-}=7000 \\
& 3 x_{11}+4 x_{12}+6 x_{13}+6 x_{14}+7 x_{15}+9 x_{16}+9 x_{17}+15000 v_{1} \\
& +6 x_{21}+4 x_{22}+8 x_{23}+6 x_{24}+6 x_{25}+10 x_{26}+9 x_{27}+20000 v_{2} \\
& +9 x_{31}+7 x_{32}+11 x_{33}+7 x_{34}+6 x_{35}+12 x_{36}+10 x_{37}+25000 v_{3} \\
& +13 x_{41}+9 x_{42}+13 x_{43}+9 x_{44}+6 x_{45}+13 x_{46}+9 x_{47}+30000 v_{4} \\
& +5 x_{51}+4 x_{52}+8 x_{53}+7 x_{54}+8 x_{55}+11 x_{56}+10 x_{57}+20000 v_{5}-d_{13}^{+}+d_{13}^{-}=458000
\end{aligned}
$$

$$
3000 w_{1}+5000 w_{2}+6000 w_{3}+7000 w_{4}+4000 w_{5}-d_{14}^{+}+d_{14}^{-}=0
$$

$$
\begin{aligned}
& v_{4}-d_{15}^{+}+d_{15}^{-}=1 \\
& v_{1}-d_{16}^{+}+d_{16}^{-}=1 \\
& v_{5}-d_{17}^{+}+d_{17}^{-}=1 \\
& v_{2}-d_{18}^{+}+d_{18}^{-}=1 \\
& v_{3}-d_{19}^{+}+d_{19}^{-}=1
\end{aligned}
$$

\section{Objective function}

Minimize $z=$

$$
\begin{aligned}
& P_{1}\left[\sum_{k=1}^{5} d_{k}^{+}+\sum_{k=6}^{12}\left(d_{k}^{+}+d_{k}^{-}\right)\right]+P_{2}\left(d_{13}^{+}\right)+P_{3}\left(d_{14}^{+}\right) \\
& +P_{4}\left(d_{15}^{+}+d_{15}^{-}\right)+P_{5}\left(d_{16}^{+}+d_{16}^{-}\right)+P_{6}\left(d_{17}^{+}+d_{17}^{-}\right)+P_{7}\left(d_{18}^{+}+d_{18}^{-}\right)+P_{8}\left(d_{19}^{+}+d_{19}^{-}\right)
\end{aligned}
$$




\section{University Library}

\section{- M M I N E R VA A gateway to Melbourne's research publications}

Minerva Access is the Institutional Repository of The University of Melbourne

Author/s:

Ho, W;Lee, CKM;Ho, GTS

Title:

Optimization of the facility location-allocation problem in a customer-driven supply chain

Date:

2008-09-01

Citation:

Ho, W., Lee, C. K. M. \& Ho, G. T. S. (2008). Optimization of the facility location-allocation problem in a customer-driven supply chain. Operations Management Research, 1 (1), pp.69-79. https://doi.org/10.1007/s12063-008-0007-x.

Persistent Link:

http://hdl.handle.net/11343/118684 